\title{
Analysis of Drug Patent in American Universities Based on Xlpat Platform
}

\author{
Bin Li \\ Jinan University library, Guangzhou, China \\ Email: 287883510@qq.com
}

How to cite this paper: Li, B. (2018) Analysis of Drug Patent in American Universities Based on Xlpat Platform. Open Journal of Social Sciences, 6, 258-273. https://doi.org/10.4236/jss.2018.612023

Received: December 5, 2018

Accepted: December 26, 2018

Published: December 29, 2018

Copyright $\odot 2018$ by author and Scientific Research Publishing Inc. This work is licensed under the Creative Commons Attribution International License (CC BY 4.0).

http://creativecommons.org/licenses/by/4.0/

\begin{abstract}
This paper uses Xlpat patent intelligence system to analyze the drug patents of American universities, and to visualize the search results and analyze the core patents. It is a summary of the research and development of drug patents in American universities, aiming to provide reference for researchers in this field.
\end{abstract}

\section{Keywords}

Patent Information Service, Patent Intelligence System, Patent Analysis

\section{Introduction}

Today's US is undoubtedly the most active market for new drug research and development, and major pharmaceutical companies are investing tens of billions of dollars in research and development funds each year (PhRMA estimated at US $\$ 51.2$ billion in 2015) to compete for new drugs. The number of innovative drugs in the United States is far ahead. The number of new drugs in China is small, and the research and development pipelines are not developed. According to the 2015 statistics, the number of products under research in the United States accounts for $48.7 \%$ of the world's total, far ahead of other countries, while ranking second in the UK, accounting for only $8.0 \%$ of the products under development; China accounts for just $4.1 \%$, falling seriously behind the United States, and the difference reached 44.6 percentage [1].

\subsection{Research Significance}

As one of the most important force in the field of pharmacy, it is of great significance in the study of drug research in American universities. Many colleges and universities are coordinating resources in the field of biomedical sciences, 
jointly promoting the construction of first-class disciplines, focusing on the integration of several interdisciplinary centers around the needs of society, and striving for first-class cooperation in production, education and research. There are five tasks for the construction of "double first-class", two of which are "improving the level of scientific research" and "focusing on the transformation of results". The purpose of drug research is to find safe, effective, high-quality, stable new drugs, so that it can be listed for human health services. Strengthening the understanding and management of the whole process of new drug research is of great significance not only for ensuring the quality of drugs, safeguarding the health of the people and the legitimate rights and interests of drugs, but also ensuring social stability, ensuring reform and opening up, and ensuring comprehensive, coordinated and sustainable development and economic construction. In September 2017, the Ministry of Education announced the long-awaited list of "Double-First Class" universities and "Double-First Class" construction disciplines. Among the list of "Double-First Class" construction disciplines, 7 Chinese traditional medicine and Chinese materia medica in 7 Chinese medicine institutions are on the list. There is one university in Guangdong Province that has entered the list, which is the Guangzhou University of Traditional Chinese Medicine [2]. Jinan University Pharmacy was selected as a "Double-First Class" construction discipline. The transformation of patent achievements is an important part of the transformation of scientific and technological achievements, and it is the task of "Double-First Class" construction. Therefore, the "Double-First Class" construction service based on the transformation of the results of the library is mainly based on patent information services.

In recent years, university libraries have achieved certain results in actively carrying out patent information services, but the choice of building a patent information service platform is not broad. Most of them use the citation analysis functions of the three patent search systems of Innography [3], WIPS [4] and Patentics [5]. They all have basic citation analysis functions, but each has its own shortcomings and it is difficult to meet the actual needs. Innography should strengthen data cleaning, WIPS needs to expand the scope of citations, and $\mathrm{Pa}$ tentics needs to enhance system stability. The three have to improve the accuracy of data retrieval.

Patent search requires a comprehensive and accurate patent search system. This paper uses the Xlpat patent intelligence system [6] to conduct patent intelligence analysis in the field of drugs in American universities. It aims to provide factual basis and required patent information for pharmaceutical technology research and development in China, and to improve the library's patent information service capabilities.

\subsection{Xlpat Patent Information System}

The Xlpat patent intelligence system covers patent data from 100 countries and regions and full-text data from 32 countries and regions. More than 22,000 standard essential patent families are indexed, including US patent transfers, 
litigation, and examiner data. In addition, the platform uses natural language processing, artificial intelligence and search intelligence technology, combined with more than 10 years of intellectual property experience of professional searchers, to further provide automation technology clusters and visualization of patent data, helping users to quickly obtain patent information.

Xlpat's advanced automation features drastically reduce the labor time spent on patent search and technical analysis, improving user productivity. The team is committed to developing original features that provide users with the best and most time-saving solutions.

On August 27, 2018, the author used the search formula: PRC: (US) and PA: (university or univ) and IPC: (A61P) to search. Wherein IPC (International Patent Classification No.) A61P means the specific therapeutic activity of a compound or pharmaceutical preparation. A total of 24,180 patent families were retrieved, and 22,710 patent families were obtained by manual denoising. Based on the above search results, the patent analysis was carried out.

\section{The Overall Situation of Drug Patents in American Universities}

\subsection{Trend Analysis of Drug Patent Applications in American Universities}

It can be seen from Figure 1 that 1975-1988 was the burgeoning period of drug patents in American universities, and the number of patent applications was small, with no more than 100. Between 1989 and 1994, the number of patent applications showed a rapid upward trend. During this period of time, the research boom of quinolone antibacterials was quickly set up, and a series of antibacterial drugs were synthesized. These antibiotics and some new antibiotics were considered to be an important milestone in the history of the development of synthetic antibacterials. From 1995 to 2000, the number of patent applications tended to be stable. From 2001 to 2010, the number of drug patent applications in American universities ushered in the second wave of growth, thanks to the application of biotechnology in pharmaceuticals and the rapid advancement of information science. Advances in structural biology, molecular biology, molecular genetics, genetics and biotechnology provide theoretical basis and technical support for the discovery of new drugs [7]. The establishment of bioinformatics, the development of biochips, the application of various information efficiency databases and information technology, can easily search for the required documents, and the research level and efficiency are greatly improved. Since 2011, the adjustment of drug patent applications in American universities has entered a stable stage, maintaining the annual level of 1000 pieces. The decline in the number of patent applications in the past two years is caused by the time lag between patent applications and publication.

\subsection{US University Drug Patent Assignee Ranking Analysis}

Figure 2 shows the top 10 recipients of drug patents in US universities. The 
University of California (Univ California) is the first in the United States with 2146 applications. The Johns Hopkins University ranked second with 646 patents. The University of Texas System (Board Of Regents, The Trustees Of The University Of Pennsylvania), the University of Michigan (The Regents Of The University Of Michigan), and Duke University (Duke University) From the third to the sixth place, each number of patent applications is more than 400 . The other top ten universities are Yale University, Emory University, Stanford University (The Board of Trustees of The Leland Stanford Junior University), and Columbia University in the City of New York.

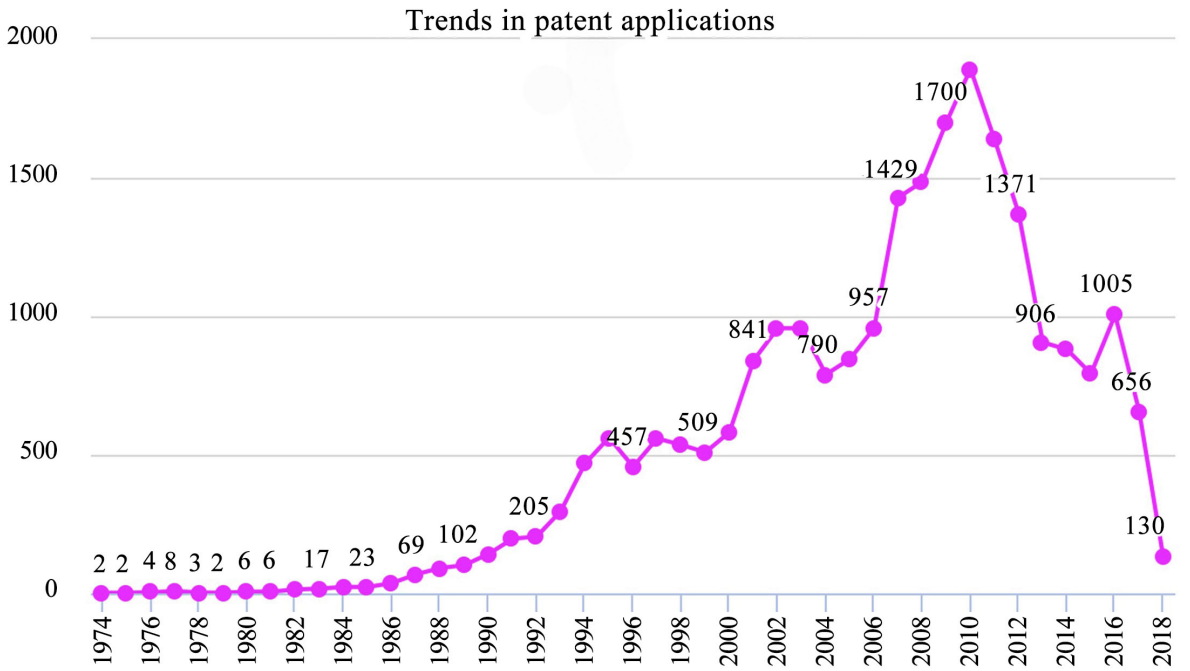

Highcharts. com

Figure 1. Trends in patent applications in the US pharmaceutical field.

Ranking of patent assignees

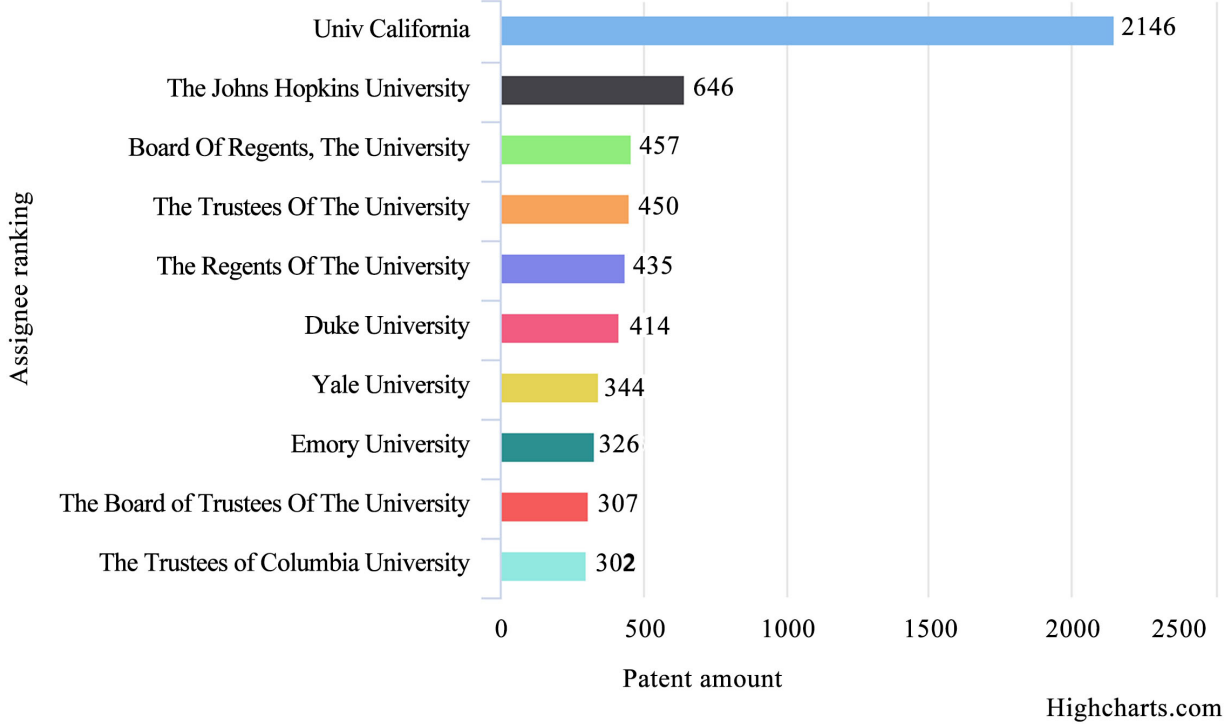

Figure 2. Ranking of patent assignees in the US pharmaceutical field. 


\subsection{Analysis of Technical Issues That Are of Primary Concern in American Universities}

Xlpat's R \& D intelligence module automatically analyzes patents with techniques such as natural language processing, machine learning, artificial intelligence, and 3D analysis to understand current innovation trends and gaps in technology, supporting companies and research institutions, universities, individual inventors, and researchers. Research and development work.

The R \& D module interprets all the information contained in the patent in a graphical format to quickly understand which problems/defects are being solved by different technical solutions, which issues assignees are studying, which issues are annual trends of basic patents for technology, and so on. This information will help to develop key R \& D decisions and guide future investment and research initiatives, such as specific areas of technology that should lead their R \& D. This will ultimately help the assignee develop new and better products and promote the expansion of existing product lines.

It can be seen from Figure 3 that the main research problems in the field of medicine in American universities are heart failure, organ failure, and treatment failure. Cardiovascular and cerebrovascular diseases have always been the number one killer of human health and an important area for scientists from all over the world. Undoubtedly, these diseases will remain the focus of human research for a long time. In the study of heart failure, the University of California, Johns Hopkins University, and Duke University are both powerful and well-received in their patent applications.

\subsection{Market Analysis of Key Universities in the United States}

One click through Xlpat competitor intelligence report analysis helps to find out the technical areas, markets, key competitors' patents and competitors' cooperation routes. As shown in Figure 4, the United States as a drug research and development power, American universities must pay attention to the local market. Most of the top ten assignees in the pharmaceutical field are centered around the US. In addition, the most concerned about American universities is the European market. At present, the European pharmaceutical market share accounts for more than $20 \%$ of the global market share [8], will inevitably lead US university applicants to go to the European market for patent layout. Japan and Australia, as world drug powers, are also receiving attention from US college applicants.

\section{Analysis and Cooperation Analysis of the Core Team of Drug Patents in Colleges and Universities across the United States}

The Xlpat patent intelligence system sets up a collaborative route analysis and dynamically displays the cooperation situation in a visualized graphic. Yale University's cooperation with other assignees in the field of pharmacy is shown 
in Figure 5. Applicants who have worked with Yale University include: The United States Government as represented by the Department of Veteran Affairs, University of South Florida, Vaxinnate Corporation, etc. In the picture, the applicant for the green logo is one-on-one with Yale University. The remaining colors represent multiple applicants who have worked with Yale University to apply together. The application for cooperation among Immport Therapeutics, The Regents of The University of California and the United States Government as represented by the Department of Veteran Affairs and Yale University is shown in Figure 6(a); Figure 6(b) shows the University of Application for cooperation with South Florida, the University of Central Florida Research Foundation and Yale University.

The Xlpat inventor cooperation application map can clearly show the cooperation among the inventors and quickly find the inventor cooperation route. As shown in Figure 7, Yale University's top three inventor teams in the field of pharmacy, are led by Stephen M Strittmatter, Ronald R Breaker and Andrew D Hamilton.

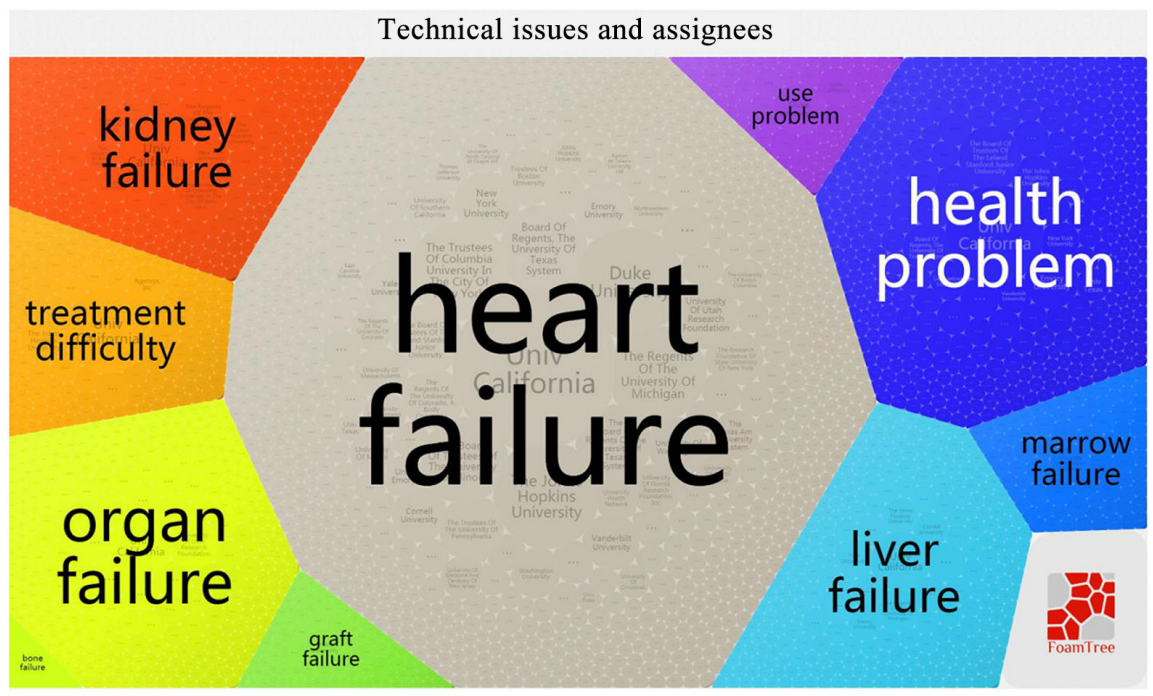

Figure 3. Technical issues and assignees in the US pharmaceutical field.

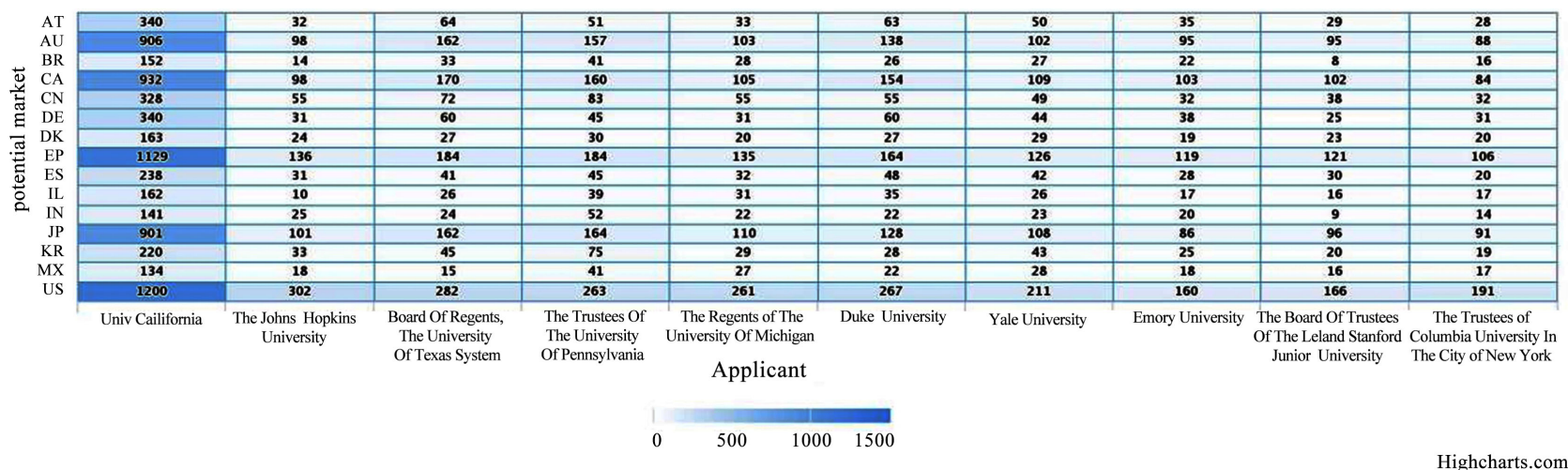

Figure 4. Distribution of patents in the US pharmaceutical field. 


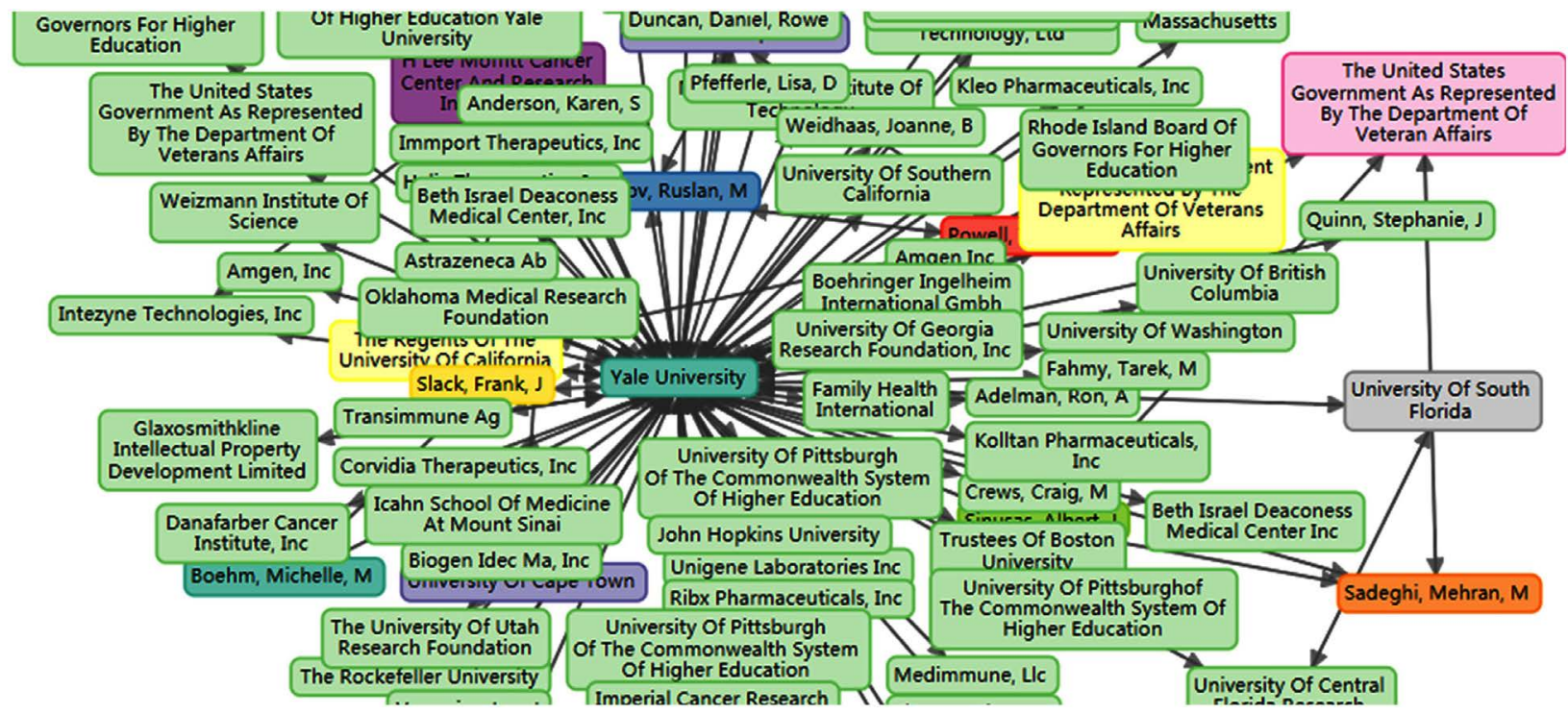

Figure 5. Overview of the Yale University assignee cooperation route.
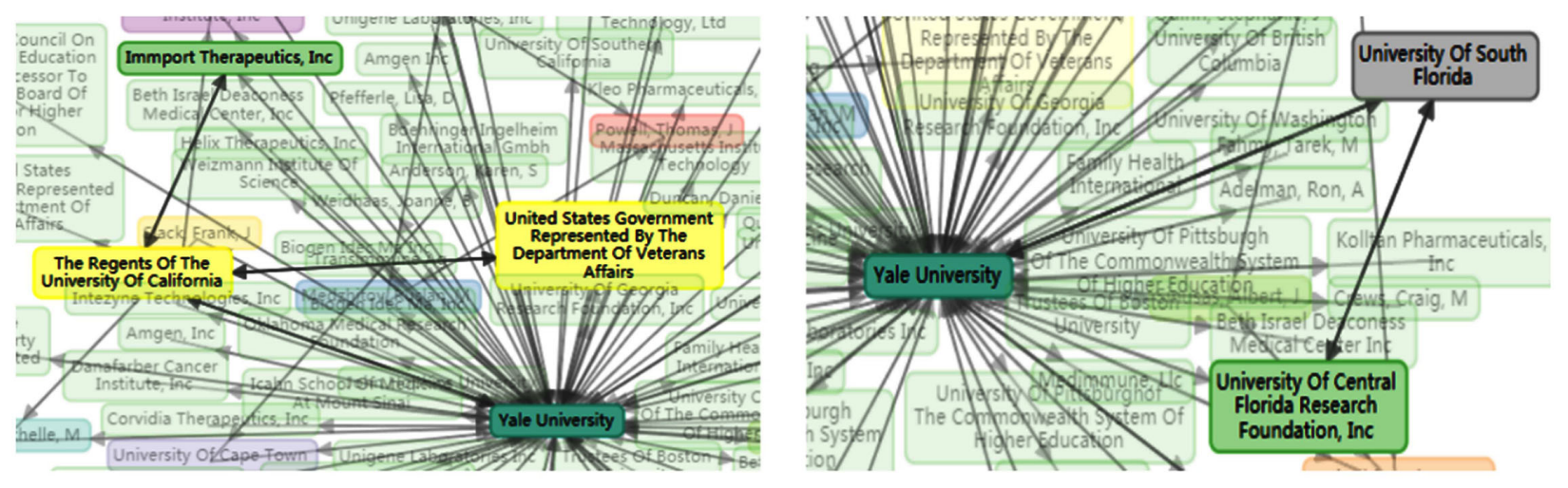

Figure 6. Yale University assignee cooperation route details.

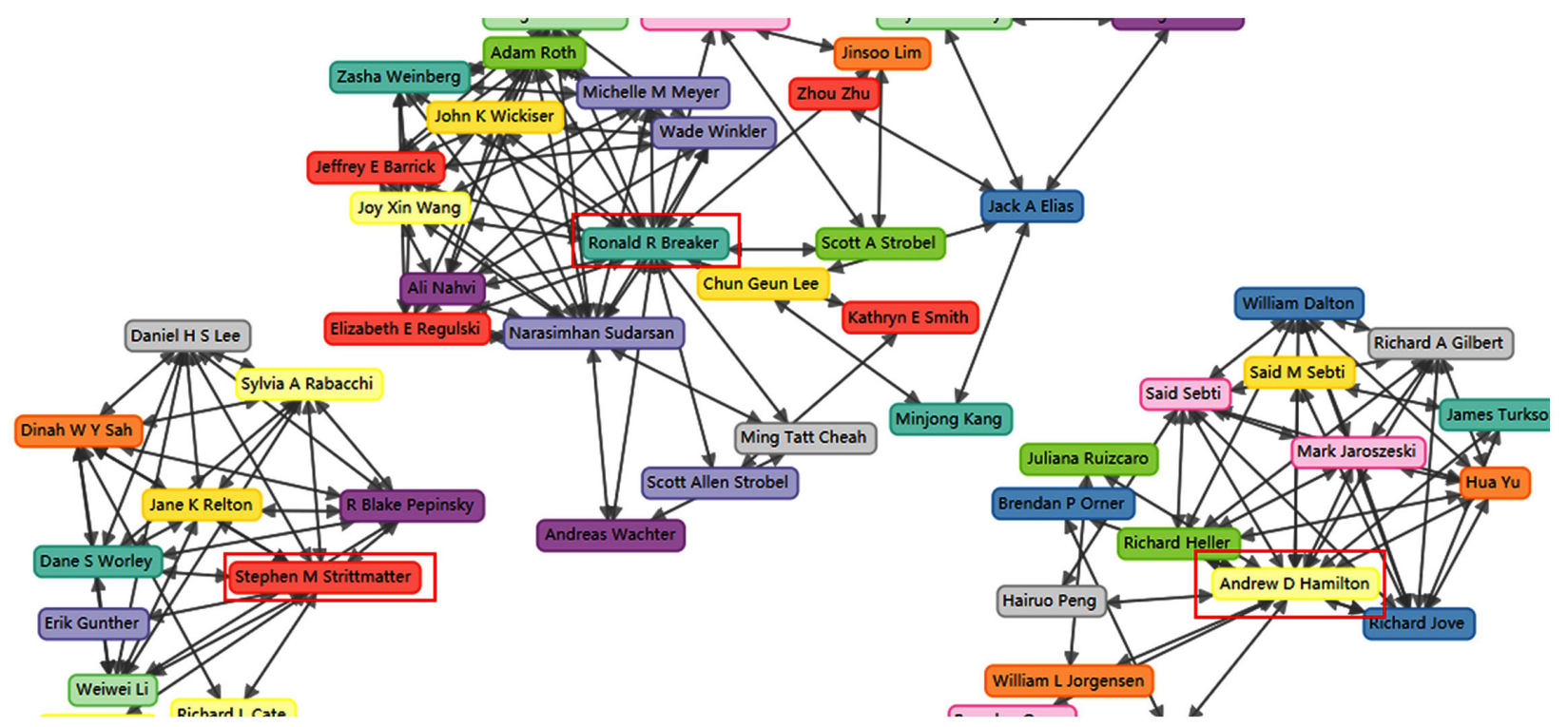

Figure 7. Yale University Inventor Team Details. 


\section{Analysis of the Concept of Drug Patent Technology in Universities across the United States}

The Xlpat technical intelligence module, the technical overview of the user's area of interest, the applicant's attention to each technology, and the distribution of technology in each country are found as shown in Figure 8, the patent-related technical concepts in the pharmaceutical field of American universities mainly focus on pharmaceutical compositions, effective Amounts, cancer cells, Nucleic Acids, and Therapeutic Agents, Immune Response, Amino Acid, Pharmaceutically Acceptable Salt, Stem Cells, and T Cells. As shown in Figure 9, the University of California is in a leading position in the top five technical concepts.

\section{Core Patent Analysis}

As shown in Figure 10, the core patent analysis of Xlpat technology directly reflects the distribution of the core patents of the top ten patent holders in this field. The color of the bubble represents the number of times of reference, the size of the bubble reflects the number of patents; the abscissa represents the year of patent disclosure; and the ordinate represents different patent holders. The number of patent citations is often an important indicator for evaluating core patents. Through Xlpat core patent analysis, it is possible to quickly screen out the number of patents that have been cited by important patentees and the proportion of core patents in applicant patents. The higher the proportion of patents that are cited more frequently, the higher the patent value of this patentee. As shown in Figure 11, the patents that have been cited more than 20 times are analyzed, and the 2008 data are analyzed. The patents, which are cited more than 20 times by Columbia University, the University of Michigan, and the University of California, are 5 articles and 11 articles accounted for 19\%, 17\% and 11\% respectively.

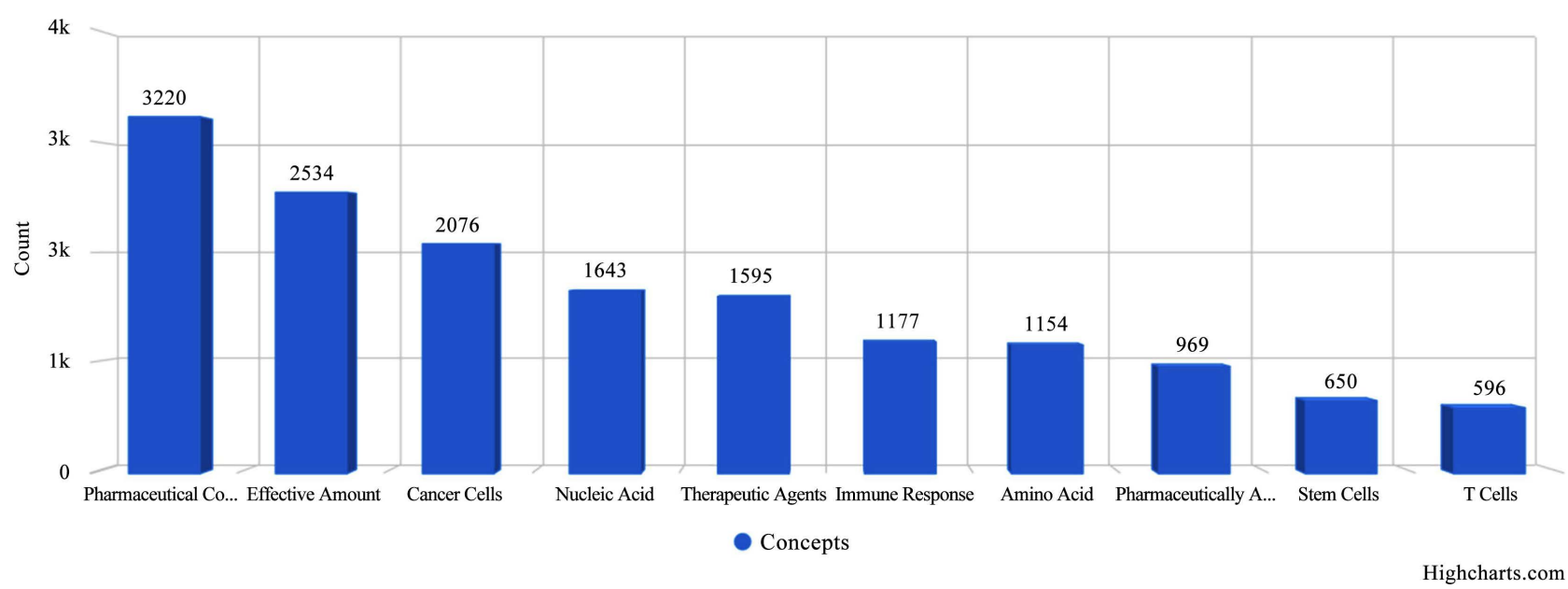

Figure 8. Ranking of patent technology concepts in the US pharmaceutical field. 


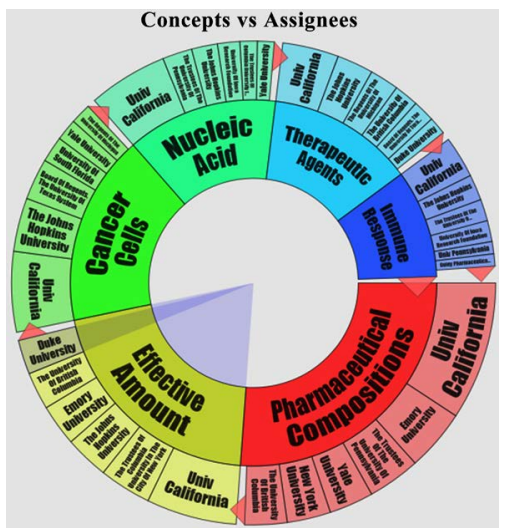

Figure 9. Patent technology concept and assignee analysis in the drug fieldof American universities.

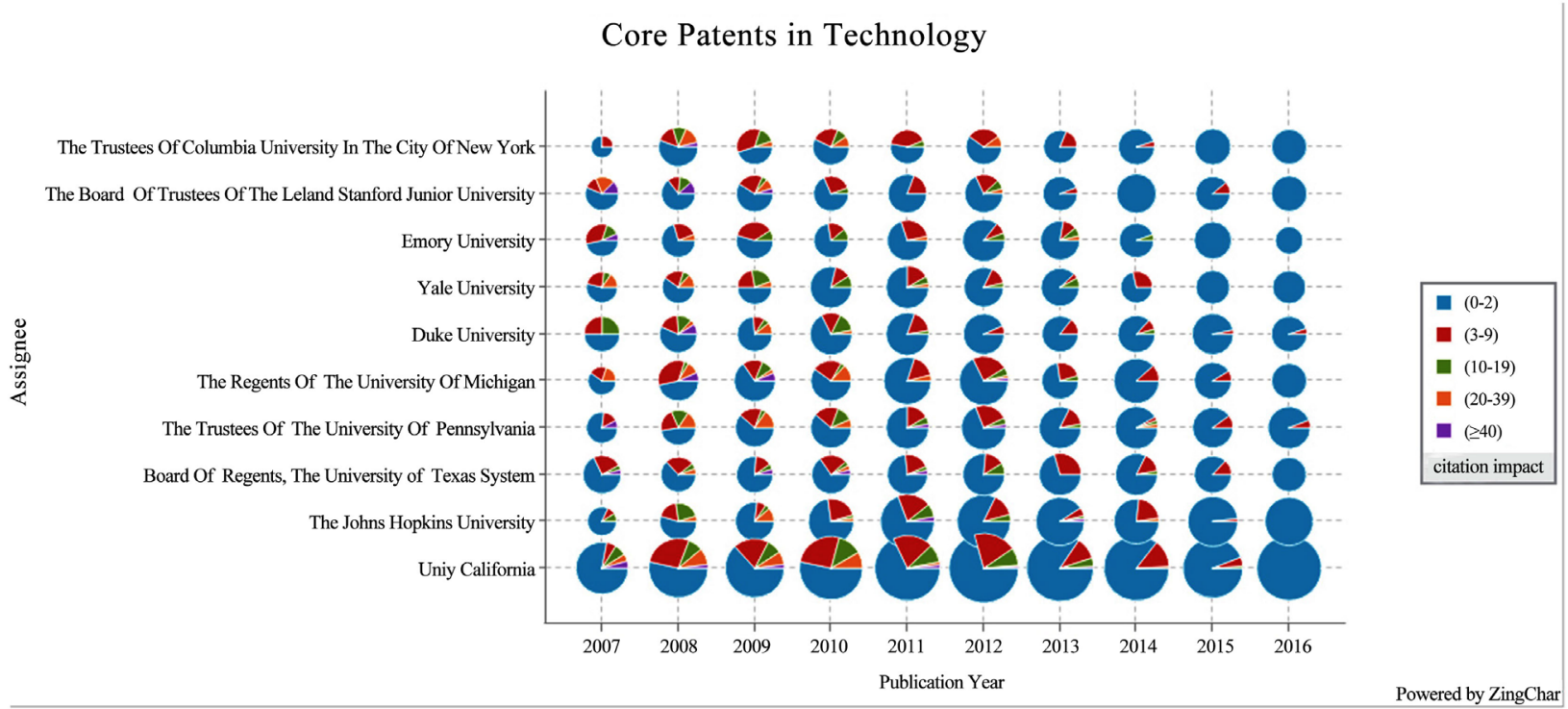

Figure 10. Analysis of the patent citation of patent assignees in the pharmaceutical field of US universities.

Core Patents in Technology

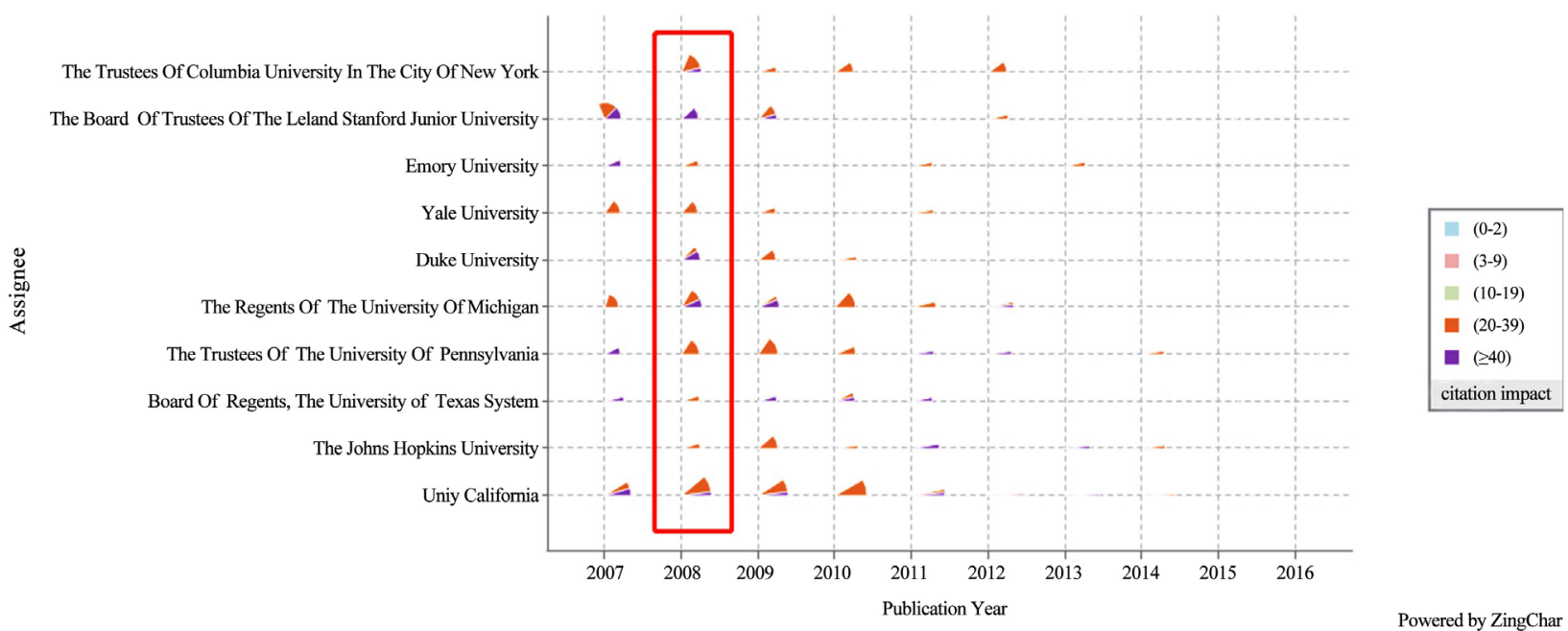

Figure 11. Analysis of core patents of patent assignees in the drug field in American universities. 


\section{Analysis of Patent Litigation}

According to PricewaterhouseCoopers, one of the world's four largest accounting firms, the number of US patent litigation cases has increased rapidly at a compound annual growth rate of $6.4 \%$ each year since 1991. In 2011, the number of patent litigation cases reached a record of 4015, which was 940 more than the number of patent litigation cases in 2004, on an increase of about 30\% [9]. Patent litigation in the United States often costs a lot of manpower and financial resources, but once the infringement facts are established, the plaintiffs often receive huge patent infringement damages. As of 2011, the median annual value of damages for the past 17 years has reached US $\$ 5.3$ million. If the patent license and compensation fees reached outside the court are settled, the plaintiffs income will be higher. In addition, the patent with litigation history is an important means for risk warning and evaluation before the product enters the market. It is also one of the important indicators for mining core patents and judging the quality and value of patents [10] [11] [12]. In order to better study litigation patents, the Xlpat Patent Intelligence System has specially set up a US litigation search module. As shown in Figure 12, by entering the company name, plaintiff, defendant, technical subject, public number, court, filing date, and closing date, patent litigation cases of the US court can be retrieved. The Xlpat Patent Intelligence Database bucket has a one-click screening for US litigation patents and can display litigation details, including case number, plaintiff, defendant, court name, and litigation filing date.

Through this function, six patents with litigation history have been screened out of the University of California in drug field as shown in Table 1.

\section{Standard Essential Patent Screening}

Standard essential patents are patents that must be used throughout the industry and are of high commercial value worldwide. Continuous R \& D innovation gives companies the opportunity to participate in the development of mainstream standards, and the substantial contribution to mainstream standards is the basis for generating and owning standard essential patents. The true standard essential patent is the product of the establishment of industry-wide rules for enterprise R \& D and innovation, and is currently the most valuable patent in the world. In fact, most of the world's most important patent licenses and transactions are centered on standard essential patents, and the commercial value of standard essential patents is also fully reflected. The study of standard essential patents has its importance and inevitability. The Xlpat patent intelligence system includes 220,000 standard essential patents and a one-click screening function to facilitate users to quickly find the necessary patents for reading standards. After systematic screening, there are five standard patents in the field of drugs in American universities, as shown in Figure 13. 
Table 1. Patent litigation in the drug field of the university of california.

\begin{tabular}{|c|c|c|c|}
\hline No. & Public No. & Patent Name & Date of Patent \\
\hline 1 & $\underline{\text { US9486474B2 }}$ & $\begin{array}{l}\text { Interstitial Therapy for Immediate Symptom } \\
\text { Relief and Chronic Therapy in Interstitial Cystitis }\end{array}$ & 20161108 \\
\hline 2 & $\underline{\text { US8183274B2 }}$ & $\begin{array}{l}\text { Treatment of Hyperproliferative Disorders } \\
\text { with Diarylhydantoin Compounds }\end{array}$ & 20120522 \\
\hline 3 & US9126941B2 & $\begin{array}{l}\text { Treatment of Hyperproliferative Disorders } \\
\text { with Diarylhydantoin Compounds }\end{array}$ & 20150908 \\
\hline 4 & $\underline{\text { US8029826B2 }}$ & $\begin{array}{l}\text { Chlorite in the Treatment of } \\
\text { Neurodegenerative Disease }\end{array}$ & 20111004 \\
\hline 5 & $\underline{\text { US5643899A }}$ & $\begin{array}{l}\text { Lipids for Epidermal Moisturization } \\
\text { and Repair of Barrier Function }\end{array}$ & 19970701 \\
\hline 6 & US4837024A & $\begin{array}{l}\text { Compositions, Articles and Mehtod } \\
\text { for Improving Wound Healing }\end{array}$ & 19890606 \\
\hline
\end{tabular}
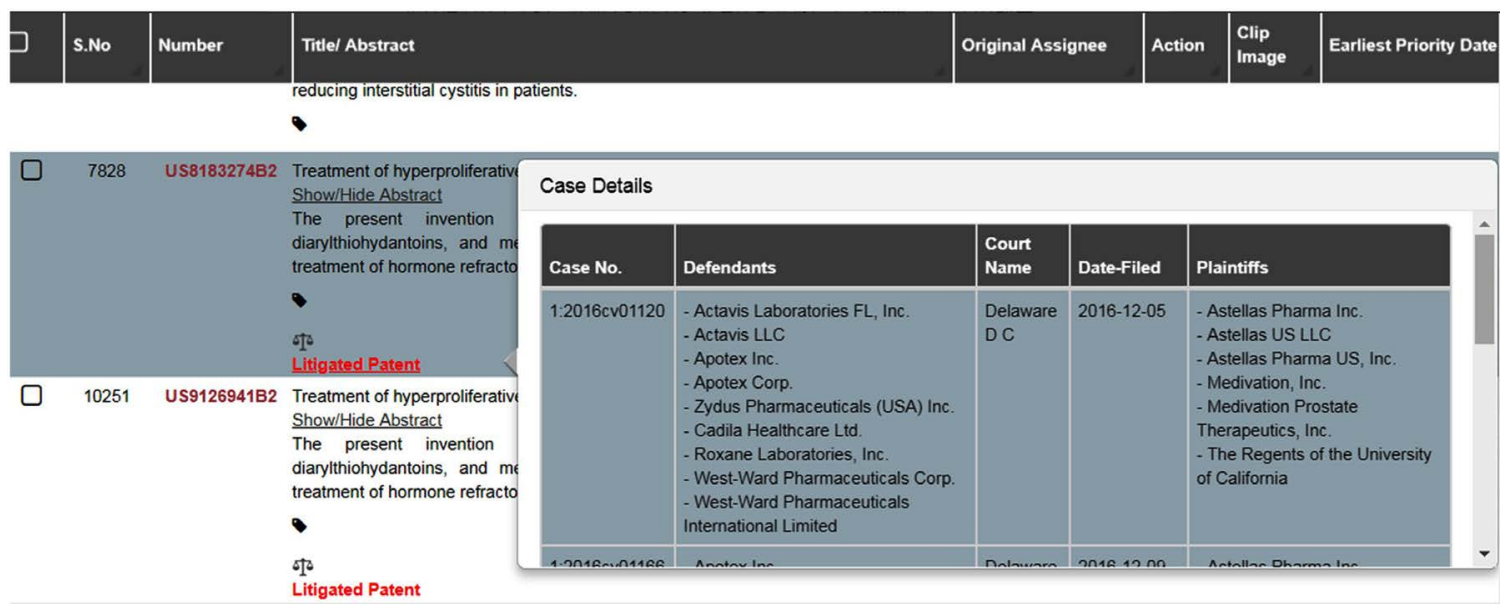

Figure 12. Patent litigation details in the drug field in US universities.

\begin{tabular}{|c|c|c|c|c|c|}
\hline S.No & Number & Title/ Abstract & Original Assignee & Publication Date & Inventors \\
\hline 9033 & US8324258B2 & $\begin{array}{l}\text {-ATPase inhibitors and related methods } \\
\text { Show/Hide Abstract } \\
\text { SEP Patent Family }\end{array}$ & $\begin{array}{l}\text { The Regents of the } \\
\text { University of Michigan }\end{array}$ & Dec 04, 2012 & $\begin{array}{l}\text { Gary D Glick } \\
\text { More }\end{array}$ \\
\hline 11007 & US8765140B2 & $\begin{array}{l}\text { DNA vaccine compositions with HIVISIV gene modifications } \\
\text { Show/Hide Abstract } \\
\text { SEP Patent }\end{array}$ & $\begin{array}{l}\text { University of Kansas } \\
\text { Medical Center }\end{array}$ & Jul 01, 2014 & $\begin{array}{l}\text { Opendra Narayan } \\
\text { More }\end{array}$ \\
\hline 11008 & US8785411B2 & $\begin{array}{l}\text { HIV DNA vaccine methods of use } \\
\text { Show/Hide Abstract } \\
\text { SEP Patent }\end{array}$ & $\begin{array}{l}\text { University of Kansas } \\
\text { Medical Center }\end{array}$ & Jul 22, 2014 & $\begin{array}{l}\text { Opendra Narayan } \\
\text { More }\end{array}$ \\
\hline 15449 & EP2200977B1 & $\begin{array}{l}\text { F1FO-ATPASE INHIBITORS AND RELATED METHODS } \\
\text { Show/Hide Abstract } \\
\text { SEP Patent Family }\end{array}$ & $\begin{array}{l}\text { The Regents of the } \\
\text { University of Michigan }\end{array}$ & Nov 09, 2016 & $\begin{array}{l}\text { GLICK Gary D } \\
\text { More }\end{array}$ \\
\hline 20761 & US6727075B2 & $\begin{array}{l}\text { Methods and compositions for determining lipid peroxidation } \\
\text { levels in oxidant stress syndromes and diseases } \\
\text { Show/Hide Abstract } \\
\text { SEP Patent }\end{array}$ & $\begin{array}{l}\text { The Trustees of the } \\
\text { University of } \\
\text { Pennsylvania } \\
\text { More }\end{array}$ & Apr 27, 2004 & $\begin{array}{c}\text { Fitzgerald Garret A } \\
\text { More }\end{array}$ \\
\hline
\end{tabular}

Figure 13. Standard essential patents in the drug field in American universities. 


\section{Patent Portfolio Analysis}

The Xlpat patent portfolio analysis module utilizes a highly intelligent system to simultaneously analyze multiple patents within a patent package. Companies that overlap with the technologies included in the patent package are analyzed through further comparison. The system identifies potential litigation patents and finds potential infringers. Taking the patent of the University of California in drug field as an example, the patent portfolio analysis was carried out. As shown in Figure 14, the system finds more than a dozen companies with technical overlaps with the University of California, and can view details of technical overlaps. For example, the University of California have two technical overlaps with Infinity Pharmaceuticals: Heterocyclic Compounds, Preparations for Medical, Dental, or Toilet Purposes; and 2 technical overlaps with Moderna Therapeutics: pharmaceutical, dental or toilet preparations, peptides (Peptides); 3 technologies overlap with Chimerix: acyclic, carbocyclic rings containing elements other than carbon, hydrogen, halogen, oxygen, nitrogen, sulfur, selenium or tellurium Or a heterocyclic compound (Acyclic, Carbocyclic Or Heterocyclic Compounds Containing Elements Other Than Carbon, Hydrogen, Halogen, Oxygen, Nitrogen, Sulfur, Selenium Or Tellurium), a heterocyclic compound, preparations for medical, dental, or toilet purposes.

As shown in Figure 15, further analysis with Infinity Pharmaceuticals as the target company, the system will score each patent of the University of California, sorting the patents in order of high to low score, the higher the score, the higher the potential value of the patent, the possibility of a patent infringement with Infinity is greater.

\section{Artificial Intelligence to Help Patent Screening}

Xlpat patent intelligence system intelligent sorting function uses artificial intelligence technology (recording user's usage habits, result selection, etc. for analysis and application), enabling users to obtain the fastest and most accurate patent documents. Through the user's definition of technical keyword relevance (high, medium, low), the system provides 10 patents to the user to choose ("receive" or "reject"). According to the system algorithm, the degree of adaptation for ranking are calculated automatically, and the most relevant patents are listed first. As shown in Figure 16, the keywords Pharmaceutical Compositions, Compounds will be selected and their relevance will be defined as high, and the system will reorder the patents in the pharmaceutical field of the University of California. The results are shown in Figure 17.

\section{Conclusions and Implications}

\subsection{Conclusion}

This paper analyzes the drug patents of American universities through the Xlpat patent intelligence system and draws the following main conclusions: 
B. Li

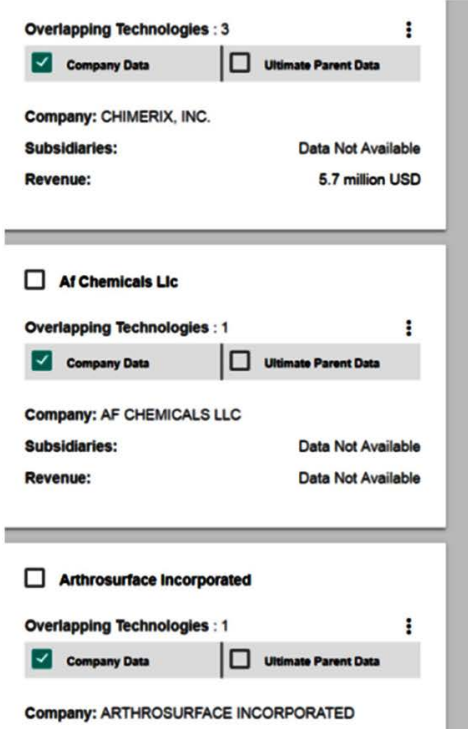

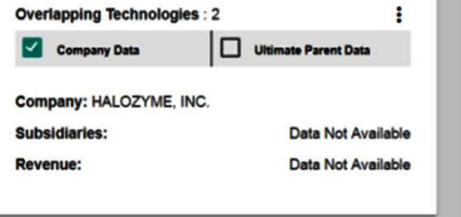
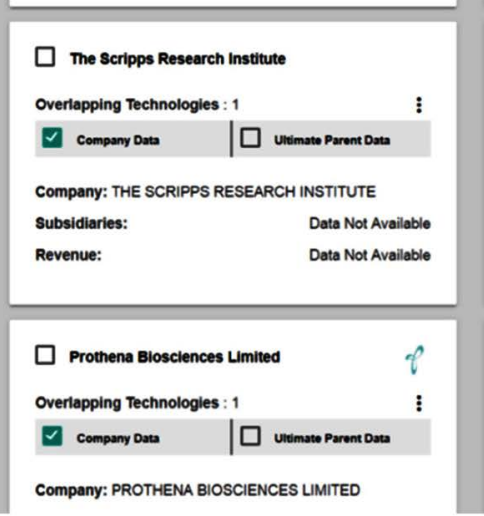

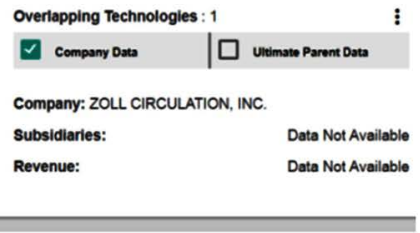

\section{$\square$ Curevac Ag}

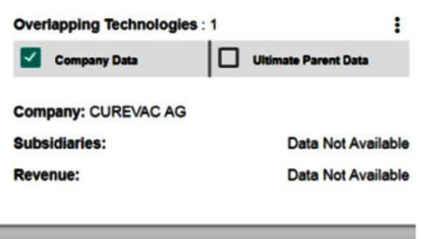

\section{$\square$ cerenis Therapeutics Holding sa}

Overlapping Technologies : 1

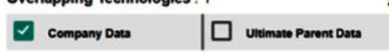

CompanY: CERENIS THERAPEUTICS HOLDING SA

Figure 14. Details of companies which have technical overlaps with the University of California.

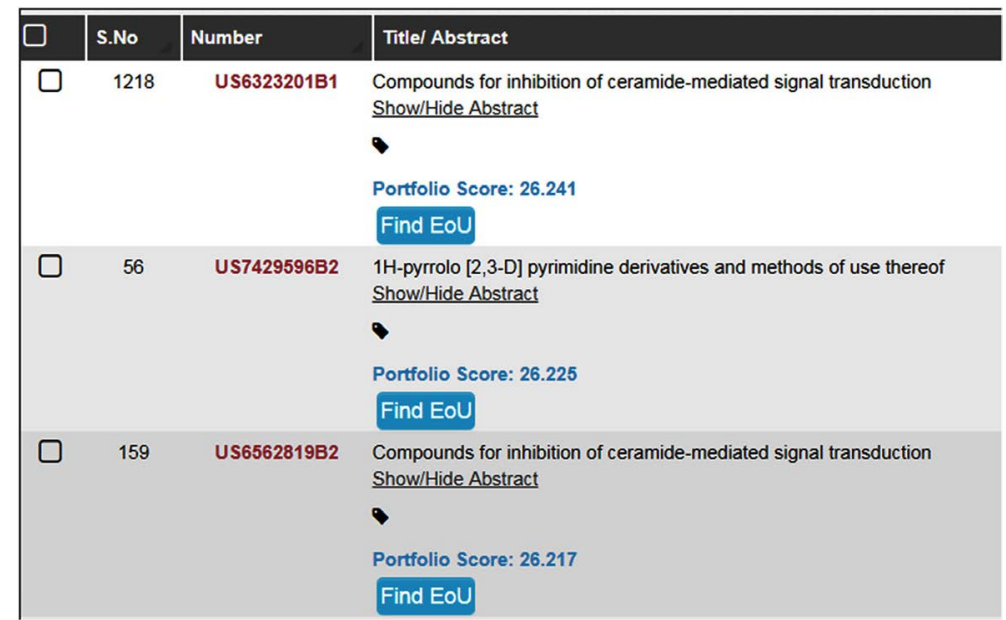

Figure 15. Rank of patent portfolio analysis score.

Search intelligence
Please help the system by entering relevant concepts
Concepts 1
Concepts 2
Concepts 3

Figure 16. Keyword selection and relevance definition. 


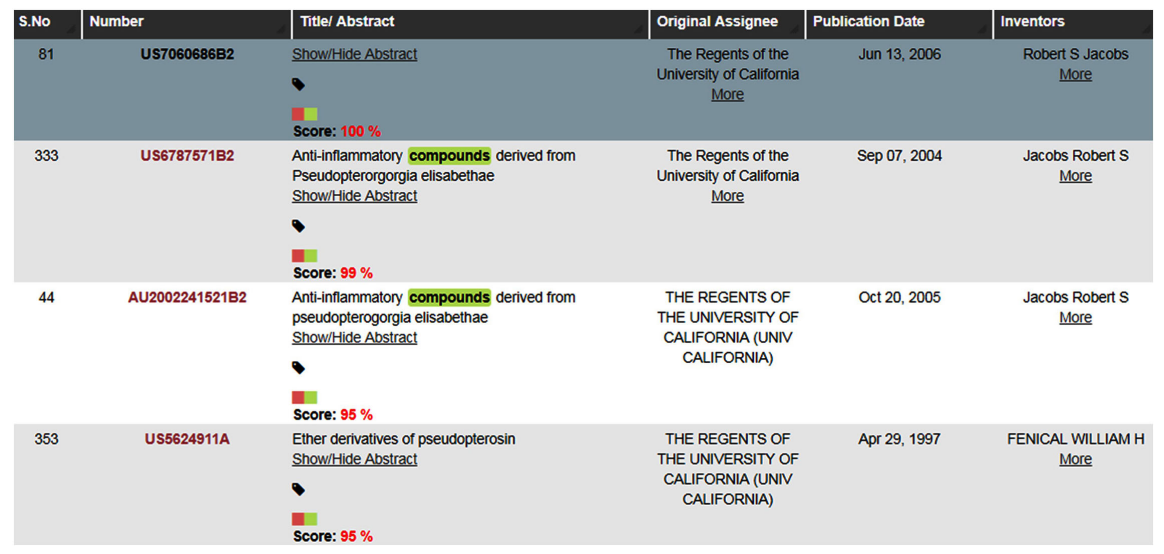

Figure 17. List of patents after reordering.

1) Between 1974 and 2010, the development of drug patents in American universities was good, and the overall trend was on the rise. Since 2011, there has been a downward trend, which may be related to the gradual maturity of drug research in American universities. After adjustment, it entered a stable stage and maintained at the level of 1000 pieces per year. The University of California and Johns Hopkins University are important universities in the US for the pharmaceutical industry. The main research problems in the drug field in American universities are heart failure, organ failure, and treatment failure. American universities mostly concern at domestic market in the drug field, followed by the European market.

2) Applicants who have worked with Yale University include: The United States Government as represented by the Department of Veteran Affairs, University of South Florida, Vaxinnate Corporation, and the like. Yale University's top three inventor teams in the drug field are led by Stephen M Strittmatter, Ronald R Breaker and Andrew D Hamilton.

3) The patent-related technical concepts in the drug field in American Universities are mainly focused on pharmaceutical compositions, effective doses, cancer cells, nucleic acids, therapeutic agents, immune responses, amino acids, pharmaceutically acceptable salts, stem cells, and T cells.

4) Columbia University, the University of Michigan, and the University of California have more core patents through the analysis of patent citations.

5) China is in a critical period of drug research and development. It must follow the international development trend and learn from the advanced experience of drug power. On the one hand, it will accelerate the pace of independent innovation in the drug field research and development, and have more excellent independent core patents; on the other hand, it should be based on continuous track and deep study, with the analysis tool Xlpat platform, of the patents of universities such as the University of California, Johns Hopkins University, Columbia University of Columbia, and the University of Michigan to further enhance R \& D strength and international competitiveness in this field of China. 


\subsection{Revelation and Summary}

The development of new drugs is one of the most complex intellectual activities of mankind, and it is also an important indicator to measure a country's comprehensive scientific and technological strength and the ability to organize social resources on a large scale. In order to achieve the above objectives, China must have a substantial improvement in the research and development capabilities of new drugs, and high-end industries have important strategic significance. Although the conditions for the development of new drug research in China are becoming more mature in the world, most Chinese companies are relatively unfamiliar with innovative drugs. The industry also lacks personal experience about the complexity of new drug R \& D and the fierce competition, so it is difficult to accurately judge the gap between Chinese companies and the world. By 2020, China will develop into a medical science and technology power and a big industrial country. Its comprehensive innovation capability will reach the top 5 in the world, and the pharmaceutical industry will enter the top 3. This is an ambitious goal set by the state and an arduous task.

In addition, the use of Xlpat patent intelligence system to study drug patents in medical universities in the United States is of great significance to the reference and reference of personnel in this field in China; Xlpat patent intelligence system provides new ideas and new paths for university intellectual property information services. Make full use of the advantages of system artificial intelligence technology, natural language processing technology and other platforms to make up for the gaps in the industry and make useful supplements; support the high-level, "Double-First Class" to promote intellectual property information platform in universities, and rely on the library construction and intellectual property information service center for the country to promote the development of different levels of service content and various service methods in universities, and to further promote the patent information service of university libraries.

This paper uses Xlpat patent intelligence system to analyze the drug patents of American universities, and to visualize the search results and analyze the core patents. However, the use of this platform for patent analysis in other industries has not yet been attempted. At the same time, there is still a lack of comparative analysis between Xlpat and Innography platforms. The advantages and disadvantages of both platforms have not been compared yet, it needs to be further research by other researchers.

\section{Project}

One of the achievements of the teaching reform project of Jinan University, "Operation of the Practical Base of Creating Maker Space in the Library: Optimizing the Construction of College Students' Entrepreneurial Environment" (JG2018024).

\section{Conflicts of Interest}

The authors declare no conflicts of interest regarding the publication of this paper. 


\section{References}

[1] Ten Charts Understanding the Current Situation of New Drug Research and Development in the World.

https://www.qianzhan.com/analyst/detail/220/180809-ecf8a5ad.html

[2] Construction of Double-First-Class Universities and Selection of Six Universities of Traditional Chinese Medicine. https://www.sohu.com/a/194057385_99975409/

[3] Innography-Login. https://app.innography.com/

[4] Construction of Double-First-Class Universities and Selection of Six Universities of Traditional Chinese Medicine. https://www.sohu.com/a/194057385_99975409

[5] Patentics. https://www.patentics.com/

[6] Xlpat labs. https://www.xlpat.com/

[7] Tian, L.P. and Zhao, Y.F. (2018) Analysis of the Effect of Gene Engineering on Drug Development. Journal of Clinical Medical Literature, No. 16.

[8] China Industrial Information Network. Current Situation of Biopharmaceutical Industry in Europe. http://www.chyxx.com/industry/201601/383912.html

[9] PricewaterhouseCoopers: A Study Report on Patent Litigation in the United States in 2012. https://www.pwc.com/

[10] Huo, C.T. (2012) The Method for Determination of Corporation Core Patents. Journal of Intelligence, No. 11, 95-99.

[11] Li, C.Y. and Shi, R. (2008) Exploration on Evaluation of Patent Quality Indicators. Journal of Modern Intelligence, 28, 146-149.

[12] Li, H.Q., Liu, Y. and Wu, S.Z. (2007) Patent Value Indicators and Their Structure. Studies in Science of Science, 25, 281-286. 